\title{
Editorial: SESMO Special Issues
}

As the journal nears the end of its second official year, we are pleased to start accepting submissions to our first two Special Issues. The first Special Issue is on Resilience of complex coupled Socio-Technical-Environmental systems through the modeling lens with guest editors Tatiana Filatova, Tina Comes (4TU Resilience Engineering Centre), Christoph Hoelscher (ETH Zurich) and Juliet Mian (Resilence Shift). This Special Issue aims to bring together cutting-edge research and international practice to offer insights into the latest scientific modelling methods, gaps, challenges and opportunities and best practice examples relating to operationalising resilience across a range of socio-technical-environmental applications. The second Special Issue is on Large-scale behavioural models of land use change with guest editors Calum Brown (Karlsruhe Institute of Technology), Tatiana Filatova (University of Twente), Birgit Müller (Helmholtz Centre for Environmental Research - UFZ), and Derek Robinson (University of Waterloo). This Special Issue is focussed on better understanding and modelling of temporal or spatial scales in land use dynamics.

We invite new proposals for Special Issues that fit within SESMO's aims and scope. Our Special Issues are cohesive collections of articles focussed on a specific contemporary theme related to socio-environmental systems modelling. The Special Issue can build on previous work and research gaps, but can also explore new and emerging terrain relevant to our aims. Although the conceptualisation of a Special Issue may be initiated in a conference or workshop, it is critical that such a proposal also builds on the original dialogue. Articles should also be canvassed from across the globe. SESMO is an open access journal with no article processing or publication charges for authors. If you have a topic to propose, please contact us to discuss further.

Tony Jakeman, Ioannis Athanasiadis \& Serena Hamilton

Contact A. Jakeman at tony.jakeman@anu.edu.au, I. Athanasiadis at ioannis.athanasiadis@wur.nl, \& S. Hamilton at serena.hamilton@anu.edu.au 